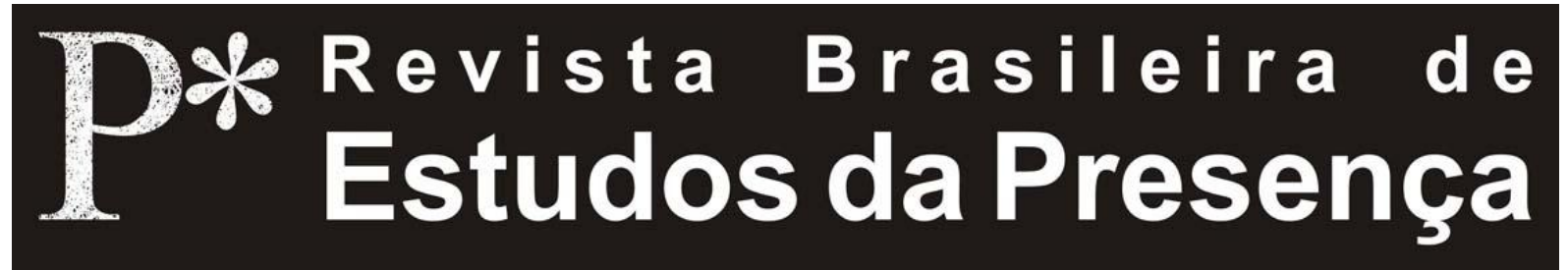

\title{
Hierarquias do Real na Mímesis Espetacular Contemporânea
}

\author{
Luiz Fernando Ramos \\ Universidade de São Paulo - USP
}

\begin{abstract}
RESUMO - Hierarquias do Real na Mímesis Espetacular Contemporânea - Parte-se da hipótese de que haja uma hierarquia de reais, menos e mais autênticos operando na avaliação da produção espetacular contemporânea. A hipervalorização da realidade dada - tomada em bruto e de pronto, enquanto elemento vivificador dos processos narrativos contemporâneos, documentários ou artificiais - é problematizada como metafísica, em contraste com obras imaginárias de mímesis espetacular que estranham e dilatam a ideia do real.
\end{abstract}

Palavras-chave: Real. Mímesis. Espetáculo. Documentário. Hierarquia.

\begin{abstract}
Hierarchy of the Real in Contemporary Performative Mimesis - It departs from the hypothesis of a hierarchy of real(s), with less and more legitimacy, operating in the evaluation of the contemporary spectacular production. The hyper valuation of a given reality, took as a ready-made an instantly, as a source of liveness in the narrative contemporary processes, documentary or artificial, is discussed and seen as metaphysic, against the imaginary works of performative mimesis, which get to strange and amplify the idea of the real.
\end{abstract}

Luiz Fernando Ramos, Hierarquias do Real na Mímesis Espetacular Contemporânea

R.bras.est.pres., Porto Alegre, v.1, n.1, p. 61-76, jan./jun., 2011.

Disponível em http://www.seer.ufrgs.br/presenca 
Keywords: The Reality. Mimesis. Performance. Documentary. Hierarchy.

\section{RÉSUMÉ - Hierarchie du Réel dans les Mimesis Performative} Contemporaine - Le point de départ est l'hypothèse de ce qu'il y a une hiérarchie de réels, plus au moins autentiques et en opération au moment d'évaluer la production spetaculaire contemporaine. La hyper évaluation de la realité - prise en brut et d'imediat, a le manière d'un élement vivan du processus narratif contemporain, documentáire ou artificiaux - est discutée entant que metaphisique en opposition aux oeuvres imaginaires de mimesis spétaculaire étranges e amplificatrices de l'idée du réel.

Mots-clés: La Realité. Mimesis. Mise-em-scène. Documentaire. Hierarchie.

Propõe-se especular sobre as hierarquias, na apreciação contemporânea das artes performativas e espetaculares, no que concerne ao real, ou aos graus de autenticidade que apresentariam. Pergunta-se se, diante de uma manifestação mínima de teatralidade ou performatividade em obra humana encenada a humanos, pressupondo um arco que fosse da absoluta simultaneidade espacial e temporal entre emissores e receptores à completa disjunção dessas partes, pudessem ser estabelecidas gradações na vivacidade, ou nas supostas qualidade e quantidade de real dessas relações. Investiga-se valorações como as do ao vivo, em detrimento do gravado, do presente in loco contra o ausente virtual e da comunicação direta sobre a mediada. Elas poderiam se desdobrar ainda, extrapolando a cena, em diferenças como a da alta e baixa definição de imagens, ou de registros verdadeiros e falsos. Essas diferenças valorativas se manifestam tanto numa dimensão estética, no teatro, na performance e nas artes visuais contemporâneas, como socioeconômica, no caso da alta definição (HD), que encarece no mercado certos produtos audiovisuais, ou político-jurídica, quando se trata de legitimar documentos ou ações por autenticação. Sem entrar na vasta questão do que seja o real em si - 
impossível de ser esgotada e atinente à filosofia pura pretende-se explorar a premissa de que há no teatro e performance contemporâneos uma tendência em qualificar como melhor, do ponto de vista do receptor, o que é ao vivo e imediato, ou como pior o que é gravado, ou mesmo transmitido, pois mais distanciado nesse contato. Ou a não validar o uso de sistemas robóticos na criação de espetáculos e instalações performativas. Arrolam-se alguns pontos de vista vetoriais sobre o tema e arrisca-se um comentário pessoal, abordando o problema pelo viés da mímesis, ou do espetáculo, e de seu desempenho na produção de reais. A perspectiva desenvolvida pode abarcar fenômenos populares, a exemplo do circo e do cinema comercial, e performances e espetáculos em que fique caracterizada uma emergência do real para além dos modelos narrativos convencionais. Discute-se, principalmente, a hipervalorização do real tomado em bruto e dado de pronto, enquanto elemento vivificador dos processos narrativos, documentários ou artificiais.

As distintas avaliações do fenômeno espetacular, relativas a serem ou não simultâneos ao ato da recepção, ou de utilizarem ou não a presença humana na sua apresentação, remetem, no limite, a dois polos antagônicos.

Em um primeiro caso, minimiza-se a especificidade do ato simultâneo de apresentação e recepção de algo espetacular em um mesmo espaço. As presenças do ator e do espectador, ambos vivos, são desmerecidas e contorna-se qualquer óbice que os veículos mediadores pudessem opor à autenticação do apresentado, mesmo quando ocorresse a ausência de qualquer ser humano na operação. Nessas situações, a obra realizada, a performance efetivada ou o espetáculo que se deu a ver, valem apenas como linguagem dada, forma e imagem, e, principalmente, pelo que concretizam no foco de apreciação do espectador ${ }^{1}$.

No segundo caso a presença humana é uma condição essencial, bem como a simultaneidade da

Luiz Fernando Ramos, Hierarquias do Real na Mímesis Espetacular Contemporânea

R.bras.est.pres., Porto Alegre, v.1, n.1, p. 61-76, jan./jun., 2011.

Disponível em http://www.seer.ufrgs.br/presenca 
recepção e a ausência de elementos estranhos, de caráter tecnológico ou instrumental, tornam-se decisivas. No limite, o fator que definiria a maior legitimidade artística do ato performativo, fosse representacional ou antimimético, seria o caráter mortal do performer, sua condição perecível apanhada diretamente no decurso do tempo e que, inexoravelmente, contaminaria a própria performance. Nesses casos, a obra, performance ou espetáculo, valeriam principalmente pela sua condição material e pela efetiva coincidência tempo espacial entre todos os seus elementos performativos singulares e os focos de apreciação que os conformariam.

Evidente que entre esses dois extremos há espaço para uma extensa gama de variações em que transitam a maioria das produções contemporâneas. De qualquer modo, é possível localizar ecos desses extremos apontados em trabalhos seminais da teoria da performance como, por exemplo, os de Philip Auslander e Herbert Blau. Será em diálogo com estes dois autores que se desenvolverá a reflexão sobre diferentes perspectivas de autenticidade localizáveis na recepção da mímesis espetacular contemporânea.

\section{Da Marionete ao Robô: o fantasma da ausência humana}

A angústia com a possibilidade de se suprimir o ser humano do processo teatral, substituindo-o pela marionete, poderia ser vista como uma manifestação romântica, tendo sua fonte no célebre texto de Heinrich Von Kleist, Sobre o Teatro de Marionetes (Kleist, 1997). A considerar, por exemplo, a prática do xamanismo nas culturas primitivas, em que há o trânsito dos xamãs para além de seus próprios corpos na pele de animais totêmicos, pode-se deduzir que o aspecto negativo desse apagamento do humano e do corporal na produção espetacular é uma ansiedade moderna ${ }^{2}$. Mesmo as tradições do teatro oriental, bem como da tragédia grega clássica, ao revestirem os atores de máscaras e adereços transfiguradores, revelam-se imunes a esse preconceito.

Luiz Fernando Ramos, Hierarquias do Real na Mímesis Espetacular Contemporânea

R.bras.est.pres., Porto Alegre, v.1, n.1, p. 61-76, jan./jun., 2011.

Disponível em http://www.seer.ufrgs.br/presenca 
De fato, os primeiros sintomas concretos dessa dificuldade localizam-se em movimentos como o naturalismo e o simbolismo no fim do século XIX. Eles tiveram problemas para lidar com o corpo humano em cena: o primeiro tratando de amenizar sua teatralidade intrínseca, o segundo sonhando com a sua sublimação e transformação em pura imagem, emanação etérea, de que a ubber marrionetten de Gordon Craig é o exemplo acabado. Mas, se o corpo era um estorvo para ambos os projetos, sua desaparição não deixava de ser uma ameaça que assombrava o teatro. Ao longo do século $\mathrm{XX}$, programas revitalizantes da cena como os de Artaud e Brecht, cada um a seu modo, intensificaram a valorização do corpo real em cena, seja na busca de sua pureza original como ocorrerá em Grotowski, seja na exacerbação de sua condição de signo, como no Buthô.

Contemporaneamente, esse debate ampliou-se e gerou uma tensão criativa entre as formas dramáticas ainda presas aos modelos miméticos convencionais, em que os atores e suas subjetividades são tomados como imprescindíveis, e formas performativas mais abertas, que pressupõem a telepresença, materiais gravados ou mesmo a utilização de robôs na enunciação cênica ${ }^{3}$.

Philip Auslander faz uma percuciente leitura da obra Abacus, do artista Sergei Shutov, exibida na 49 Bienal de Veneza e analisada por ele na perspectiva da arte da performance. Trata-se de uma instalação com 40 figuras vestidas de preto, que são de fato robôs, olhando uma porta e rezando simultaneamente em diversas línguas e realizando movimentos regulares e ritmados. Auslander se pergunta sobre a validade de pensar a obra como uma performance, e argumenta a favor dessa alternativa como possível, a despeito de se poder considerá-la simplesmente como um mecanismo de repetição. Assim, se a ação daqueles robôs pode ser tomada em um sentido estrito, o de perfazerem algo, como quando falamos do desempenho de um motor, podem também implicar na fruição por um espectador de uma performance artística. No geral, essa definição

Luiz Fernando Ramos, Hierarquias do Real na Mímesis Espetacular Contemporânea

R.bras.est.pres., Porto Alegre, v.1, n.1, p. 61-76, jan./jun., 2011.

Disponível em http://www.seer.ufrgs.br/presenca 
dependerá, segundo ele, do contexto e do tipo de arte que se considere esteja sendo realizada. Se fossemos além da ideia de artes especializadas - teatro, dança, performance - poderíamos estender esse pressuposto a qualquer mímesis espetacular que se propusesse a afetar, entrar em risco de contato, com um observador atento. Assim, a reza dos robôs não seria tomada como uma caixa de música, ou um carrossel girando vazio, máquina de variações programadas, mas, da perspectiva do espectador, como um discurso cênico potencialmente efetivo.

Um espetáculo recente de Denis Marleau, Os Cegos, de Maeterlink, encenava este texto clássico do simbolismo, que possui treze personagens, utilizando-se apenas de televisores estrategicamente camuflados no escuro da cena. Ainda que o efeito obtido, quase sobrenatural, fosse de cabeças suspensas no vazio do breu, com um grau de verossimilhança acentuado de que eram mesmo atores presentes dizendo suas falas ao vivo, o que o espectador confrontava de fato, e pelo que se deixava afetar, eram televisores exibindo material prégravado ${ }^{4}$. Importante salientar que, a despeito da ousadia desse verdadeiro golpe de ilusão, a encenação, na medida em que era absolutamente fiel ao texto, reproduzia disciplinadamente a curva dramática original. Esse fato só enriquece o ponto que se está aqui desenvolvendo, pois evidencia que no plano do teatro convencional, da ficção dramática, a ausência do humano imediato, ao vivo, presente, pode mesmo ser superada por uma fantasmagoria do humano e alcançar plenamente a efetivação da mímesis espetacular.

Em outro exemplo de instalação performativa, desta vez na Bienal de São Paulo de 2010, a obra Bandeira Branca de Nuno Ramos, também dispunha à fruição do público caixas de som dispostas sobre totens de areia, numa combinação de volumes compactos de aparência sólida e consistência real frágil, a veicularem algumas canções populares em volume baixo. A intensidade do som era determinada pela convivência no

Luiz Fernando Ramos, Hierarquias do Real na Mímesis Espetacular Contemporânea

R.bras.est.pres., Porto Alegre, v.1, n.1, p. 61-76, jan./jun., 2011.

Disponível em http://www.seer.ufrgs.br/presenca 
mesmo espaço de exposição - todo eixo central da principal rampa do prédio da Bienal cercado por uma tela negra - de alguns urubus. O funcionamento das caixas de som e a presença ostensiva dos pássaros combinavam-se entre si no que seriam os elementos performativos, dispensando, pois, a presença humana tanto quanto no exemplo de Abacus. Dois aspectos são destacáveis neste caso. O primeiro é o de que aqui ocorre uma mímesis espetacular fora dos padrões dramáticos, como sintaxe de imagens e objetos concretos postos em jogo com a imaginação e o entendimento eventuais do fruidor. Mais do que o modelo da peça que se encaixa, no quebracabeça, ou da ficha que cai e conecta, na grade referencial do realismo convencional, aqui a ficha não para de rolar em suspenso, como uma biruta movimentada por vento incerto, e os sentidos vagam com as possibilidades em aberto. Estamos no campo da performance art e não no do drama, mas a mímesis, ou o espetáculo, não deixa de se operar. $\mathrm{O}$ segundo aspecto desse exemplo, importante de destacar, é o fato de que a presença dos urubus, para além de sua dimensão performativa, cumpre o papel de introduzir no jogo conceitual proposto um quantum de real que fricciona com a própria performance, já que não cessa de confrontá-la e reivindicar a interrupção daquela fábula artística. Curiosamente, a interrupção precoce da exibição da obra, provocada em função de protestos de ambientalistas pela presença dos urubus, concretizou uma tensão interna, e não explicitada espetacularmente até então, entre a dimensão conceitual e estética da obra e os seus elementos concretos, de sua realidade em bruto.

Este último exemplo sugere que se encaminhe a discussão dos aspectos mais ligados à questão da presença, definida em contraposição a uma humanidade remota - materiais gravados, automação e virtualidade -, para os aspectos da hipervalorização em diversos processos artísticos contemporâneos, espetaculares ou fílmicos, do que se poderia chamar de emergência intempestiva do real ${ }^{5}$. Antes, porém, especula-se mais um pouco sobre a questão da vivacidade.

Luiz Fernando Ramos, Hierarquias do Real na Mímesis Espetacular Contemporânea R.bras.est.pres., Porto Alegre, v.1, n.1, p. 61-76, jan./jun., 2011. 
Philip Auslander oferece um notável exemplo para se pensar a ideia do ao vivo, e seu valor excedente frente ao gravado, como mais real, atual ou autêntico. Buscando uma definição de dicionário ele descobre a primeira aparição do termo e do sentido a ele associado em um manual interno da BBC dos anos 1930 (Auslander, 2007). Ali, ao vivo, surge para informar os ouvintes da rádio inglesa de que aquela transmissão não era gravada, mas acontecia simultaneamente à audição. Ou seja, a definição surgia em função de uma realidade anterior, já existente, com o que contrastava. Desde o fim do século XIX já havia aparelhos de reprodução de sons gravados. A informação sobre se o som provinha de um disco gravado ou de performance simultânea à audição se fazia necessária, agora, pela impossibilidade dos ouvintes discriminarem a verdadeira origem do som ouvido. Transposta para as atuais tecnologias de registro em tempo real da vida humana, das câmaras de vigilância caseiras às das grandes transmissões esportivas, a valorização dessa atualidade cresceu, mas também se banalizou. Paradoxalmente, quanto mais potencializadas pela tecnologia digital, as imagens e sons transmitidos ao vivo mais perdem relevância, sendo exemplo disso a utilização constante pelas redes do recurso do quase ao vivo, quando cenas e fatos recém acontecidos são reproduzidos. $\mathrm{O}$ ao vivo ainda mantém alguma aura, mas já não parece tão relevante essa sincronia, na transmissão, do elemento performativo com a recepção. Em uma realidade digitalizada, em que tudo é acessível a partir de fontes perenes, a própria TV aberta, que em seus tempos heróicos chegou a fazer teatro ao vivo, torna-se cada vez mais um estoque de imagens que são acessadas pontualmente. Ao mesmo tempo, como foi observado, no plano da mímesis espetacular, seja nos teatros mais tradicionais, seja no campo das instalações, performances, obras de site specific ou da chamada Live $A r t$, o real imediato é cada vez mais alvo de cobiça, como um objeto a ser escavado no tempo e imiscuído nas obras. 
Herbert Blau lembra que a noção e o valor da vivacidade (liveness) entrou nas preocupações da teoria da performance através dos paradigmas de autenticidade que se constituíram no trânsito entre a cena, o cinema e a televisão. Ele concorda com Auslander que o ao vivo só pode existir dentro de uma economia de reprodução, e que o seu próprio culto tornou-se um produto da mídia. Mas pontua que, se a vivacidade não poderia ser pensada antes do fonógrafo e da fotografia (ainda que mesmo o Festival de Dionísio na Grécia antiga fizesse parte de uma economia de reprodução), a própria ideia de um teatro vivo (living theater), e seu pressuposto implícito de que existam presenças mais qualificadas do que outras, têm de ser historicizadas. Oportunamente diferencia o que sua geração considerava como tal - apenas o que não era teatro filmado - do sentido que a expressão ganhou depois do histórico grupo de Julian Beck e Judith Malina, o famoso Living. Blau percebe, no teatro do grupo e em todo ambiente de dissidência dos anos 1960 que o cercou, a valorização da vivacidade por oposição à desumanização. Reconhece que essa reação humanista e o risco que lhe assombrava manifestaram-se igualmente no cinema, na própria televisão, e, mais recentemente, na vida virtual do mundo cibernético. Segundo ele, a desumanização será, na apoteose da realidade virtual, "a condição (i)material da vivacidade" (Blau, 2007, p. 535). $O$ virtual quer ser real, almeja e finge essa presença diferenciada. Por mais que o espaço cibernético tenda, cada vez mais, a dissolver presenças vivas, ou mediá-las, essa evanescente presença continua reproduzindo, independente da mídia, a busca de uma atualidade mais autêntica. Resta à mímesis espetacular, em quaisquer que sejam seus meios operativos nessa utopia de presença, conformar-se em estar aquém, ou a ter menos, como sugere Blau.

Diante dessas teorizações que confirmam um campo de hierarquia de reais, ou de camadas de realidade distintamente qualificadas, interessa aqui refletir, ainda, sobre a tendência dominante, seja no cinema, como no

Luiz Fernando Ramos, Hierarquias do Real na Mímesis Espetacular Contemporânea

R.bras.est.pres., Porto Alegre, v.1, n.1, p. 61-76, jan./jun., 2011.

Disponível em http://www.seer.ufrgs.br/presenca 
teatro e na performance, de valorização máxima dos elementos documentários sobre os ficcionais, dos espaços urbanos e seus significados históricos sobre os espaços ditos convencionais, dos elementos performativos e biográficos sobre os artifícios de caracterização e mascaramento.

As ideias de que haja uma legitimidade maior na história real, que aconteceu, do que na inventada; no espaço não preparado para o teatro, e que em tese abriga a verdadeira vida, do que no espaço funcionalmente preparado para encenações; no desempenho espontâneo e improvisado do que no ensaiado, projetam uma mesma crença no presente e na presença. Essa atualidade ideal aparece como um fator de revitalização para o teatro, a arte e a sociedade.

Quando as ditas vanguardas históricas lançaram seus reptos a mímesis e propugnaram por eliminar a repetição da vida na representação, significando aí eliminar a própria representação para alcançar diretamente a vida, não só refletiam as ideias de Nietzsche como anunciavam os tempos atuais, em que o imediato e o aqui agora se tornaram valores capitais. Claro que numa sociedade hiper mediatizada essa pulsão parece quase necessária, como reação natural e instintiva estratégia de sobrevivência.

Há, por exemplo, no campo estrito do teatro, uma leitura dominante, de reconhecimento, dos diversos grupos brasileiros que se lançaram à realidade sem freios e com voracidade, abarcando-a como matéria prima e ecoando seja uma disposição política de transformação, seja uma ampliação de fronteiras na fruição da arte, como propõe a estética relacional (Bourriaud, 2007). É preciso cogitar que há um nítido travo metafísico e idealista nesse elogio indiscriminado do real. Talvez, procedimentos altamente estetizados, ou convencionais, ou ainda plenamente ficcionais, sejam muito mais potentes para rasgarem a realidade e valorizarem efetivamente tanto $o$ presente como a presença. Quer dizer, não é o real em bruto, simplesmente tomado, que atualiza por si só a vida.

Luiz Fernando Ramos, Hierarquias do Real na Mímesis Espetacular Contemporânea

R.bras.est.pres., Porto Alegre, v.1, n.1, p. 61-76, jan./jun., 2011.

Disponível em http://www.seer.ufrgs.br/presenca 
Essa ideia de Duchamp foi boa, mas, e de clichê, é morta. O que cria a atualização é a mímesis, que liga alguém a algo, provoca uma conexão e se efetiva como acontecimento, ainda que indeterminado e sem identificações. Pode ser o mito, que nas formas mais populares de narrativa - circo, cinema, quadrinhos, literatura, teatro - enreda o leitor espectador na ficção; ou as formas contemporâneas de espetáculo, que operam com uma margem de invenção possível e que, trabalhando ou não elementos tomados da realidade, permanecem indecifráveis. É em exemplos alternativos desse segundo grupo, dos que trabalham no campo da invenção, que se pretende focar nos comentários finais dessa reflexão. Primeiro, com exemplos em que há um contato imediato com a matéria bruta do real, e em que a poiesis é extraída daí, ainda que sem mitificar o presente e a presença. Depois, com exemplos que retomam, numa perspectiva radical, a poiesis como criação de realidade, ou, simplesmente, como ficção.

John Cage disse que "[...] não há tal coisa como um espaço vazio, ou um tempo vazio" (Cage apud Blau, 2007, p. 533). Herbert Blau lê esta afirmação como premissa da ideia de Cage de que a música experimental se torna teatro, que é para o compositor o que "[...] está continuamente se tornando aquilo que está se tornando". Blau conclui com sua própria formulação de que "[...] não haverá espaço vazio se houver alguém olhando" (Blau, 2007, p. 533).

Cage ecoa Gertrude Stein, que foi pioneira no se deter sobre a fenomenologia do ver no teatro, preocupada, de fato, com o ver e ouvir simultâneos (Stein, 1967), e antecipa uma obra como a de Tino Seghal e suas exposições vazias, ou seus espaços expositivos sem objetos de arte, dispondo apenas o espaço e o tempo para relações possíveis a serem tecidas pelos olhos e sentidos que por ali passarem.

Obras como a peça de Cage 4'33, cuja matéria prima é o silêncio, ou os milhares de pés de filme em 16 milímetros não filmados por Nan June Paik e exibidos em

Luiz Fernando Ramos, Hierarquias do Real na Mímesis Espetacular Contemporânea

R.bras.est.pres., Porto Alegre, v.1, n.1, p. 61-76, jan./jun., 2011.

Disponível em http://www.seer.ufrgs.br/presenca 
vídeos opacos no início dos anos 1960, impenetráveis à visão mas potenciais disparadores da imaginação, inventam um fruidor criador. $O$ teatro talvez seja $o$ território onde é mais difícil radicalizar essa experiência de oferecer a ausência de obra como obra. No silente espaço vazio, totalmente escuro, há um mundo de possibilidades, mas o difícil é trazer para dentro e sustentar um espectador lá. No entanto, alguns projetos tem caminhado nessa direção. $\mathrm{O}$ último Beckett, das peças televisivas e do retorno à prosa do início, é um criador numa penumbra crescentemente intensificada. $\mathrm{Na}$ lida com as ondas eletrônicas do vídeo trabalhou a luminosidade nos limites mínimos possíveis e deixou um rastro a ser explorado. Trabalhos do Club Noir, em São Paulo, tem desenvolvido esse caminho. Combinando um uso concentrado e altamente poético da palavra, com uma redução drástica dos recursos cênicos, a companhia de Roberto Alvim e Juliana Galdino tem realizado espetáculos cada vez mais escuros, que projetam para a consciência íntima do espectador (o seu filme mental interno) a produção de imagens simultânea ao espetáculo. De algum modo, ao atentar à condição exclusiva da fruição teatral, de suportar a escuridão e se bastar só com os outros sentidos na apreensão de um acontecimento cênico, o Club Noir atualiza sobremaneira o real imediato no foco de apreciação, operando em regiões de luminosidade interditadas às formas fílmicas. Em paralelo, a despeito do minimalismo das imagens, ali não se abdica de construí-las intensas e marcantes, no que se dialoga, também, com o segundo grupo de exemplos mencionado, focando em casos de mímesis explícitas e heterocósmicas, como diria Stephen Halliwell, de criação de novos mundos (Halliwell, 2002).

Nesse campo, uma das referências seminais será o fotógrafo, cineasta e performer norte-americano Jack Smith, que pioneiramente pontuou, no fim dos anos 1950, a necessidade dos olhos dos artistas da fotografia, do cinema, do teatro e da performance se libertarem da linha e atentarem para a superfície, deixarem o mythos e

Luiz Fernando Ramos, Hierarquias do Real na Mímesis Espetacular Contemporânea

R.bras.est.pres., Porto Alegre, v.1, n.1, p. 61-76, jan./jun., 2011.

Disponível em http://www.seer.ufrgs.br/presenca 
buscarem o opsis, deixarem de ser cegos e passarem a ver. As próprias fotos e filmes de Smith já trazem sintetizada a explosão de imagens e do imaginário que transcorreria nos anos 1960, e que só faria se acelerar com a internet e com o incremento das percepções áudio tácteis em nosso cotidiano, como previu Vilém Flusser (Flusser, 2002).

No aspecto que se está aqui destacando, na tensão entre as dimensões documentárias e ficcionais, Smith é também exemplar (Smith, 1997). Trabalhando com o mínimo disponível, o que estivesse à mão, com o lixo até, ele proporá sempre a alquimia de transformar esse nada em sofisticada elaboração de linguagem, ou de imagem. Mesmo tematicamente, ao eleger como seu ícone maior Maria Montez, estrela da República Dominicana que brilhou em alguns filmes da Universal na década de 1940, reforçava essa inversão de prioridades potencialmente subversiva: dos discursos mais conceituais e eruditos para o estímulo à intuição e liberação das dimensões sensuais e sensitivas; da crescente mercantilização da arte para a prática de um processo artístico sempre inacabado e em contínuo colapso.

Dois exemplos da cena contemporânea podem ser reconhecidos como herdeiros dessa radicalidade de Smith, principalmente pela profusa avalanche de imagens com que instauraram novas possibilidades de visualização do mundo. Um deles é Mathew Barney, cuja obra transita pelas artes visuais, pela performance, pelo cinema e pela ficção literária e não se acomoda em nenhum desses nichos. Ao fim e ao cabo, a série/exposição/encenação/filme Cremaster é um grande constructo ficcional em que a mímesis, como já foi sugerido, opera com o indecidível, ou com a impossibilidade de repouso da dúvida sobre o que, afinal, se perfaz diante de nós e sobre como pode ser acomodado numa leitura/visagem. A mesma potência de provocar essa inquietação produtiva, tendendo necessariamente a estimular o receptor na criação de seus próprios parâmetros, aparece nos espetáculos da Societá Rafaello

Luiz Fernando Ramos, Hierarquias do Real na Mímesis Espetacular Contemporânea

R.bras.est.pres., Porto Alegre, v.1, n.1, p. 61-76, jan./jun., 2011.

Disponível em http://www.seer.ufrgs.br/presenca 
Sanzio. A ideia de Romeo Castellucci, de uma iconoclastia da iconoclastia, já aponta para o universo da visibilidade, e de como se trata menos de operar contra as imagens e sua transformação em fator de dominação e mercantilização, e mais de, no terreno do inimigo, subvertendo sua lógica produtiva, construir novas imagens impensadas e alimentar uma nova imaginação nos espectadores (Castellucci, 2001).

Para concluir, cabe retomar a questão de uma localizada hierarquia de reais, operante na valorização de certos processos artísticos em detrimento de outros. Crêse que ficou relativizada a hipótese de que obras que lidam diretamente com materiais brutos da realidade tenham, a princípio, uma validade ou atualidade maior que outras, que partiriam da supressão de qualquer produto a ser fruído, ou de uma hipérbole de elementos ficcionais indecifráveis. Ao contrário, a sugestão que fica insinuada é que esses últimos exemplos, exatamente por recusarem essa identificação absoluta com o real dado, e tencionarem a dimensão perceptiva com elementos estranhos a ele, tenham muito mais chance de atualizar o ato de fruição.

\section{Notas}

${ }^{1} \mathrm{O}$ conceito de foco de apreciação foi desenvolvido por David Davies em Art as Performance, Oxford, Blackwell, 2004.

${ }^{2}$ Aqui cabe diferenciar a ideia de desumanização daquela implícita no preconceito antiteatralista, que já aparece em Platão e que rebaixa o ato interpretativo do ator, associando-o às capacidades imitativas do macaco. Nesse caso a animalização não suprime o humano, mas o degrada. O temor da supressão parece estar associado à revolução industrial e à ideia realizada da máquina realizando as tarefas humanas.

${ }^{3}$ É necessário pontuar que a recusa à prótese, à tecnologia, ao gravado e aos recursos de automação não é generalizada e aparece aceita e assimilada tanto no âmbito dos espetáculos da Broadway como no de encenadores radicais como Romeu Castelucci, ou inovadores, como Robert Lepage. 
${ }^{4}$ O espetáculo Os Cegos foi apresentado em São Paulo, numa temporada de quatro dias no Sesc Pinheiros,entre 29 de julho e 1 de agosto de 2010. Criação da companhia d'UBU, de Denis Marleau, e apoiada pelo Museu de Arte Contemporânea de Montréal e pelo Festival d'Avignon, tinha o subtítulo de Tecnologia Fantasmagórica.

5 Josette Feral e Sílvia Fernandes são teóricas que vem, a partir da constituição da performatividade como conceito operador, apontando esta emergência em diversas obras e reconhecendo-a como tendência característica de nosso tempo. A intempestividade implica na ideia de um real que emerge de forma involuntária.

${ }^{6}$ CAGE, John. Experimental Music, un Silence: lectures and writing. Middletown, Conn.: Wesleyan University Press, 1974.

\section{Referências}

AUSLANDER, Philip. Live from Cyberspace, or, I Was Sitting at My Computer This Guy Appeared He Tought I Was a Bot. In: REINELT, Janele; ROACH, Joseph; ARBOUR, Ann (Org.). Critical Theory and Performance. The University of Michigan Press, 2007. P. 526-531.

AUSLANDER, Philip. Humanoid Boogie: reflections on robotic performance. In: KRASNER, David; SALTZT, David; ARBOUR, Ann (Org.). Staging Philosophy intersections of theater, performance and philosophy. The University of Michigan Press, 2006. P. 87-103.

BLAU, Herbert. Virtually Yours: presence, liveness, lessnes. In: REINELT, Janele; ROACH, Joseph; ARBOUR, Ann (Org.). Critical Theory and Performance. The University of Michigan Press, 2007. P. 532-546.

BLAU, Herbert. Seeming, Seeming: the ilusion of enough. In: ACKERMAN, Alan; PUCHNER, Martin (Org.). Against Theatre - creative destructions on the modernist stage. Houndmills: Palgrave Macmillan, 2006. P. 231-247.

BOURRIAUD, Nicolas. Estética Relacional. São Paulo: Martins Fontes, 2007.

CASTELLUCCI, Romeo. A Iconoclastia da Cena e o Retorno do Corpo. A potência carnal do teatro. In: Epopea Della Polvere. Il Teatro della Societas Rafaello Sanzio 1992-1999. Milano: Ubulibri, 2001. P. 43-90.

FLUSSER, Vilém. Line and Surface. In: STRÖHL, Andreas (Org.). Writings. Minneapolis: University of Minnesota Press, 2002. P. 21-34.

HALLIWELL, Stephen. The Aesthetic of Mimesis: ancient texts and modern problems. Princeton: Princeton University Press, 2002.

Luiz Fernando Ramos, Hierarquias do Real na Mímesis Espetacular Contemporânea

R.bras.est.pres., Porto Alegre, v.1, n.1, p. 61-76, jan./jun., 2011.

Disponível em http://www.seer.ufrgs.br/presenca 
KLEIST, von Kleist. Sobre o Teatro de Marionetes. Tradução de Pedro Sussekind. Rio de Kaneiro: Sette Letras, 1997.

SMITH, Jack. The Writings of Jack Smith: wait for me at the bottom of the poll. HOBERMAN, Jim; LEFFINGWELL, Edward (Org.). New York: High Risk Books, ICA/P.S.I, 1997.

STEIN, Gertrude. Plays. In: Look at Me Now ad Here I Am - writings and lectures (1909-45). London: Penguin Books, 1967.

Luiz Fernando Ramos é professor, doutor, do Departamento de Artes Cênicas da Escola de Comunicações e Artes da USP, desde 1998. Professor do programa de PósGraduação em Artes Cênicas da USP desde 2000.

E-mail: 1fr@usp.br

Recebido em abril de 2011

Aprovado em junho de 2011 